\title{
Quality of life in patients with chronic obstructive pulmonary disease undergoing respiratory rehabilitation
}

\author{
Paula Cristina Dias Rocha Cavaleiro Saraiva * \\ Sousa Martins Hospital, Guarda, Portugal
}

Received: January 3, 2014

DOI: $10.5430 /$ jnep.v5n2p78

Accepted: August 24, $2014 \quad$ Online Published: November 30, 2014

URL: http://dx.doi.org/10.5430/jnep.v5n2p78

\begin{abstract}
Background: Chronic obstructive pulmonary disease (COPD) is a disease characterized by chronic airflow limitation, with significant systemic effects, which causes disability that results in the progressive deterioration of the patients' quality of life. In addition to the pharmacological treatment, respiratory rehabilitation is one of the fundamental pillars of their treatment.

Methods: This study aimed to measure the quality of life level of patients with COPD, who are undergoing respiratory rehabilitation. The empirical research was based on a cross-sectional, with correlation guidance, based on a quantitative approach and on the application of the SGRQ questionnaire to each participant. The study included 80 patients with COPD. From these, 38 did respiratory rehabilitation and 42 did not. All belonging to the area of influence of the Sousa Martins Hospital (ULS Guarda, EPE). The results were processed in SPSS (version 19).

Results: Among the 80 patients who participated in the study, there were 65 male and 15 female. The average age was 70.89 years. The results obtained showed that all the participants in this study have decreased their quality of life in all domains (symptoms, activity, impact). In general, the quality of life, according to its average values, corresponds to 60.38\%. In addition, there is a greater decrease of quality of life in those patients who did not undergo respiratory rehabilitation. These present average values higher in all domains: symptoms (58.87\%), activity (78.31\%), impact (53.58\%) and total quality of life (62.16\%).
\end{abstract}

Conclusion: This study found that patients who did not undergo respiratory rehabilitation have a worse quality of life when compared with patients receiving this therapy.

Key Words: Chronic obstructive pulmonary disease, Respiratory rehabilitation, Quality of life, Saint George's respiratory questionnaire

\section{Introduction}

The pathologies of the respiratory system constitute a health problem of great magnitude, with enormous impact on health resources in indirect and direct costs. Specifically, chronic obstructive pulmonary disease (COPD) is a problem of growing importance, which derives large number of morbidity, loss of quality of life and mortality. ${ }^{[1]}$ The World Health Organization (WHO) estimates that the disease has reached 210 million people worldwide, with about 64 million symptomatic cases. ${ }^{[2]}$

The COPD can be defined as "a preventable and treatable disease with a pulmonary component (characterized by chronic airflow limitation) and with significant systemic effects that contribute to the severity of clinical manifestations". ${ }^{2]}$ Concurrently, according to the same authors, COPD causes a series of changes that lead to limitation of

\footnotetext{
*Correspondence: Paula Cristina Dias Rocha Cavaleiro Saraiva; Email: rochapinhel@gmail.com; Address: Sousa Martins Hospital, Guarda, Portugal.
} 
exercise tolerance and translates into a progressive deterioration of the quality of life of patients. It is an incapacitating disease that often determines psychological disorders that may culminate in anxiety or depression, progressively leading to decreased quality of life. ${ }^{[3]}$ Also ONDR ${ }^{[4]}$ states that the patient with COPD will progressively worsen their health, their lifestyle and the quality of life will be deteriorating, requiring integrated and continuous care, tending to follow the evolution of the disease, so that when other more differentiated treatment is needed, it will bring them some comfort. Besides being one of the leading causes of death also worldwide, COPD seriously compromises the quality of life of patients with this condition. ${ }^{[5]}$ And this is an important aspect that concerns rehabilitation nurses, and requires an appropriate intervention.

Apart from the distinguished scientific progress of the last decades, it is not possible to obtain a cure for most diseases, and implementation of some effective treatments already available is barred by economic imperatives. In this context, there have been important advances in treatments that extend life, leading to a quantitative increase in the survival of patients who did not always correspond to a qualitative impact that would warrant the significant recovery of their physical, emotional, or social status. In this sense, measuring this impact, it has become crucial in the selection of more effective treatments, as well as the allocation of resources and implementation health programs. ${ }^{[6]}$

In this context of increased life expectancy and consequent prevalence of chronic diseases, the term health-related quality of life has gained increasing importance in the scientific context. Some factors related to the limitations imposed by the disease itself and treatment influence the perception of patients with chronic disease on their health and quality of life. For this reason, the assessment of quality of life constitutes a supporting aspect in checking the impact of worsening health and implemented treatments. ${ }^{[3,7]}$

The treatment of COPD exacerbations, at home is substantially (about 40 times) cheaper than inpatient, ${ }^{[4]}$ therefore the development of treatment strategies and monitoring of these patients during periods inter-admissions should be incremented. Effectively, patients were usually treated in a hospital exclusively in the context of worsening of their disease which can now be treated in the inter-hospitalization periods, reducing the frequency of hospital admissions, with consequent cost reduction, clearly contributing to increased comfort and quality of life for patients and families. Under the treatment of COPD, respiratory rehabilitation appears as adjunctive therapy to pharmacological treatment, aimed at achieving an effective improvement in the performance of ADL with subsequent translation in increased quality of life. Also Vettorazzi ${ }^{[8]}$ supports this view, stating that among the therapies prescribed respiratory rehabilitation is unequivocally a multidisciplinary treatment strategy, which aims to improve the quality of life of patients and reintegrating them into society. ${ }^{[8]}$ Thus, the rehabilitation nurse, with a specialized knowledge and techniques in the field of respiratory rehabilitation, appears as an essential element within the multidisciplinary team. Indeed, nowadays, it is widely recognized by many the influence of various chronic diseases on quality of life of individuals and their carriers. However, although it is "consensual the importance of measuring quality of life in the evaluation and selection of treatments, in practice this has occurred too infrequently". ${ }^{[6]}$ In view of that scenario, within chronic diseases, COPD emerges as dominant, so that studies in this area deserve special attention. In fact, it is essential to know the quality of life of patients suffering from this chronic disease, the use of instruments for checking the impact of the disease on their quality of life is needed. In parallel it is necessary to know the factors that influence the perception of these individuals about this concept. ${ }^{[3]}$

In this line of thought, the problem of the present study focuses on: "Measuring the quality of life of patients with COPD undergoing Respiratory Rehabilitation" in order to achieve the following overall objective: Measure the level of quality of life in patients with COPD undergoing Respiratory Rehabilitation.

In order to achieve this goal, we carried out a quantitative, non-experimental, correlational and cross-sectional study, with a non-probability sample of individuals with COPD who underwent Respiratory Rehabilitation and another sample of patients with COPD who did not undergo Respiratory Rehabilitation and belonging to the area of - influence of the Sousa Martins Hospital (ULS Guarda, EPE).

The present study was based on the application of a specific questionnaire of respiratory disease, the Saint George's Respiratory Questionnaire (SGRQ), which contains three components (symptoms, activity and impacts).

\section{Methods}

\subsection{Design}

For this research, a cross-sectional quantitative study and a characteristic design of a non-experimental study, ${ }^{[9]}$ also called post-facto study ${ }^{[10]}$ or correlational and observational study ${ }^{[11]}$ was performed.

\subsection{Data collection and participants}

In this study, we have resorted to an accidental non-random sample, composed of 80 individuals with COPD, belonging to the geographical area of - influence of the Hospital de Sousa Martins (ULS Guarda, EPE), of which 38 underwent respiratory rehabilitation and the remaining 42 did not undergo this therapy. This choice was mainly driven by two factors: personal knowledge derived from professional relationships with many elements of the health care team of this institution on the one hand and being an institution located 
in my area on the other.

To minimize the impact of possible sampling errors an eligibility criteria was established. Thus, the patients were included in the study had, concomitantly, two fundamental requirements: have COPD and some having done respiratory rehabilitation.

In the context of a quantitative study, as is this one, it resorted to the use of a form. This measuring instrument is based on a formal list of questions, whose fulfillment is the responsibility of the investigator himself. From another point of view, the choice of form was motivated by their length and complexity, avoiding in this way errors and omissions in their completion. However, we are aware of the deleterious effect that the presence of the investigator may have in some responses.

Structurally, the instrument of data collection was composed of 5 sections: one aimed at socio-demographic characteristics, followed by the circumstantial characterization and clinical characterization, one specifically with regard to the scale of quality of life (St. George's Respiratory Questionnaire - SGRQ), and finally the familiar functionality (Apgar family).

Of the total of 80 COPD patients who constituted the sample, 65 were male and 15 female. Regarding age was found between 45 and 92 years, with an average of 70.89 years. With an average weight of $68.58 \mathrm{~kg}$, and an average height of $1.64 \mathrm{~m}$. The great majority of patients were married $(81.2 \%)$ and a large proportion $(78.8 \%)$ lived with the respective spouse. Half of the respondents resided in urban areas $(50 \%)$. Regarding employment status, it was found that $83.3 \%$ of patients were retired, and $14.1 \%$ developed an occupation, of which, $87.5 \%$ played an activity within the primary sector. The majority of the sample (43.8\%) moves to health services through family transport, lying at an average distance of $7.39 \mathrm{~km}$. Of the sample, 54 people were taking medication habitually, mainly addressed to the respiratory, cardiovascular and metabolic disorders. Considering the assistance provided by health professionals, it was found that such a significant part of the sample $(93.8 \%)$ did not receive help from these professionals, at home. Most patients (45\%) had a COPD grade IV, verifying that equal percentage of patients needed to domiciliary oxygen therapy. The median time of diagnosis was 7.53 years. Regarding smoking, most of the patients $(68.8 \%)$ reported not having these habits today. However, $80 \%$ of patients were perentórios in stating that they possessed these habits in the past. On average patients were exposed to tobacco smoke over 23.10 years. On average patients had 0.98 admissions in the last year related to their breathing problem. Note that patients who are not complied with respiratory rehabilitation are those who have a higher mean number of hospitalizations (1.31) in the last year and there are highly significant difference statistics $(t=-4.284, p=.000)$. Most patients $(55 \%)$ considered their current health status as moderate, this being the highest percentage for the patients who have completed respiratory rehabilitation $(60.5 \%$ to $50.0 \%)$. Of the remainder, $31.2 \%$ consider it really bad, this being more significant percentage in the group of patients that did not fulfill respiratory rehabilitation $(38.1 \%$ to $23.7 \mathrm{~A}$ significant part $(37.5 \%)$ of patients consider to make part of a highly functional family, and an upcoming percentage $(36.2 \%)$ considered to have a family with moderate dysfunction.

\subsection{Instrument}

The Saint George's Respiratory Questionnaire (SGRQ) is the most used specific assessment questionnaire specific of quality of life the most used and the most suitable on respiratory disease. ${ }^{[12]}$ This questionnaire addresses the clinical part of the respiratory disease on daily life activities, evaluates subjective well-being and detects changes in health under the effect of therapy. ${ }^{[13,14]}$ The authorship of SGRQ is attributed to the Jones, Baveystock and Quirk ${ }^{[15]}$ and has been validated for the Portuguese language by Sousa and colleagues $^{[16]}$ and translated into the portuguese population by Taveira and Ferreira.

The instrument referred above consists of 50 items, with 76 of weights responses distributed over three domains: ${ }^{[15]}$

- The domain "Symptoms" - corresponds to the first part of the questionnaire, consists of eight items and assesses respiratory symptoms, frequency and severity;

- The domain "Activity" - corresponds to section 2 and section 6 of the second part of the questionnaire, consisting of 16 items. This domain assesses the activities that cause or are limited by respiratory distress;

- The domain "Psychosocial Impact" which corresponds to sections $1,3,4,5,7$ of the second part of the questionnaire consists of 26 items and assesses the control of the disease, the patient's expectations, the drugs and how the disease affects in daily life and their well-being.

To calculate the quality of life of each individual is taken the sum of the weights of each item belonging to each domain is then divided by the maximum potential that can be achieved. The score for each domain is given as a percentage, calculated by the coefficient, visible in the following equation (see Table 1). ${ }^{[15]}$

Table 1: Coefficient for calculating the SGRQ questionnaire

Score $=\frac{\sum \text { obtained value } \times 100}{\sum \text { maximum possibility }}$

The instrument reveals a good quality of life when the results are close to 0 (zero) and worse quality of life with close 
to $100 .^{[3,17]}$ Therefore, the score of each part that integrates the questionnaire is then converted to a percentage.

According to Jones, Quirk and Baveystock, ${ }^{[15]}$ amounts to $10 \%$ show that the quality of life is still considered normal; results above $10 \%$ indicate an abnormal condition. Parallel with changes equal or greater than $4 \%$ after an intervention in any field or in the total sum of points, indicate a significant change in the quality of life of patients.

For the assessment of family functioning the family Apgar scale created by Smilkstein was adopted to the Portuguese population by Azevedo and Matos. ${ }^{[18]}$ It is based on five questions that intend to assess the subject's perception about the quality of your family relationships, and includes the following dimensions: intra-family-adaptation; - interaction and communication; - growth and development - affection; - devotion to family.

\subsection{Ethical issues}

In order to collect the data for this study, authorization was needed by the institution, in this case, ULS Guarda. The application for authorization to the health institution, in case the ULS Guarda, to allow the application of the instrument for data collection on the premises of the said unit was prepared. Moreover, there was concern in obtaining informed consent from all study participants and ensuring anonymity and confidentiality to the data obtained.

\subsection{Data analysis}

To conduct this investigation, we considered a set of variables that was necessary and fundamental to the statistical treatment: socio-demographic variables (gender, age, marital status, weight, height, residence, mean cohabitant, monthly earnings, educational attainment, employment status, occupation); circumstantial variables (accessibility to health services, distance to health services, help from health professionals in the household), clinical variables (time of diagnosis, stage of disease, domiciliary oxygen therapy, smoking ) and family functioning.

In the data analysis we resorted to the descriptive and inferential statistics. The descriptive statistics, determined were: absolute frequencies and percentages, minimum, maximum, average, standard deviation, and coefficient of variation. With regard to inferential statistics were used parametric tests (ANOVA and $t$ test) and nonparametric (MannWhitney and Kruskal-Wallis) were used to establish the relationships between the variables were used. The level of statistical significance was fixed at $p<.05$ in this study. The statistical treatment of the data was performed using SPSS software 19.0 - Statistical Package For Social Science.

Given the problem and the objectives of the study and following the theoretical foundations that support the idea that the quality of life of patients with COPD undergoing respiratory rehabilitation is conditioned by variables of context

Published by Sciedu Press socio-demographic, circumstantial and clinical, the following hypotheses were formulated:

(1) Socio-demographic variables (gender, age, marital status, weight, height, residence, mean cohabitant, monthly earnings, educational attainment, employment status, occupation) influence the quality of life of patients with COPD.

(2) Circumstantial characteristics (accessibility to health services, distance to health services, help from health professionals at home) influence quality of life of patients with COPD.

(3) Clinical characteristics (time of diagnosis, stage of disease, domiciliary oxygen therapy, smoking) influence quality of life of patients with COPD.

(4) The family functioning has a significant effect on the quality of life of patients with COPD.

\section{Results}

\subsection{The quality of life for COPD patients undergo- ing respiratory rehabilitation}

The respondents presented an compromised quality of life in all domains (symptoms, activity, impact). The activities domains of QOL was the one that found most compromised, in the sample considered $(75.32 \%)$, being more prevalent in the group of patients who did not perform respiratory rehabilitation $(78.31 \%)$. Regarding the symptom domain, it was found that patients had an average percentage of $58.62 \%$, with the largest representation in patients who did not undergo respiratory rehabilitation program (58.87

Regarding the total quality of life, it was found that patients have an average percentage of 60.38 being more prevalent in the group of patients that did not comply respiratory rehabilitation program $(62.16 \%$ to $58.41 \%$ ) (see Table 2).

Due to this it was found that those patients who did not undergo pulmonary rehabilitation had a worse quality of life compared to patients receiving this therapy.

It was found that the SGRQ domain that has the highest average value is what measures the activities (75.32\%), followed immediately by the symptoms $(58.62 \%)$ and finally the dominion concerning the impact $(52.19 \%)$. In parallel, the total QOL obtained has a minimum value of 3.48 and a maximum 93.40, with an average of 60.38 (see Table 3).

\subsection{Relationship between quality of life and socio- demographic variables}

We proceeded to study the relationship between the variable quality of life and socio-demographic variables: gender, age, marital status, weight, height, residence, mean cohabitant, monthly earnings, educational attainment, employment status and occupation. 
Table 2: Distribution of the sample according to the implementation of the Respiratory Rehabilitation program and QOL, according to domains: symptoms, activity, psychosocial impact

\begin{tabular}{lllllll}
\hline & $\begin{array}{c}\text { Respiratory } \\
\text { Rehabilitation }\end{array}$ & Sim & & Não & \multicolumn{3}{c}{ Total } \\
\cline { 2 - 7 } Domains & $\mathbf{N}^{\mathbf{0}}$ & $\bar{X}$ & $\mathbf{N}^{\mathbf{o}}$ & $\bar{X}$ & $\mathbf{N}^{\mathbf{o}}$ & $\bar{X}$ \\
\hline Symptoms & 38 & 58.35 & 42 & 58.87 & 80 & 58.62 \\
Activity & 38 & 72.02 & 42 & 78.31 & 80 & 75.32 \\
Impact & 38 & 50.65 & 42 & 53.58 & 80 & 52.19 \\
Total Quality of Life & 38 & 58.41 & 42 & 62.16 & 80 & 60.38 \\
\hline
\end{tabular}

Table 3: Descriptive analysis of QOL and its domains (scores in \%)

\begin{tabular}{llllcl}
\hline & $\mathbf{N}$ & $\mathbf{M n}$ & $\mathbf{M x}$ & $\bar{X}$ & $\mathbf{D p}$ \\
\hline Symptoms & 80 & 5.49 & 95.49 & 58.62 & 19.83 \\
Activity & 80 & 0.0 & 100.0 & 75.32 & 18.87 \\
Impact & 80 & 0.0 & 89.74 & 52.19 & 18.69 \\
Total Quality of Life & 80 & 3.48 & 93.40 & 60.38 & 16.39 \\
\hline
\end{tabular}

Analyzing the age groups it was found that the largest average percentage of activities domain (84.95\%), the impact domain $(64.08 \%)$ and total QVD $(69.89 \%)$ corresponded to patients aged less than 79 years. So, the older patients had worse quality of life in the areas considered. In this case, the differences between groups are statistically significant, in the activities domain and Total QOL, and very significant in the impact domain, which is confirmed by ANOVA.

Regarding marital status, it was found that the largest average percentage of the activity domain corresponded to the unmarried patients $(94.88 \%)$, the differences being statistically significant among the three groups in this area, as revealed by ANOVA.

Regarding the height, it was found that patients who were measured between $1.63 \mathrm{~m}$ and $1.66 \mathrm{~m}$ had a higher value average percentage in the symptoms domain, with statistically significant differences in this area, which is proven by the test ANOVA.

Regarding residence, it was found that patients who lived in the village were those with higher mean percentage in the activity domain $(81.99 \%)$, with a statistically significant difference in this area, as revealed ANOVA.

With regard to the mean cohabitant, the data revealed that patients who were living with father/mother had a higher mean percentage in the activity domain $(95.22 \%)$ In this case, the differences between groups are statistically significant, in the activities and impact domains, and Total QVD, which is proven by Kruskal - Wallis.

Regarding the employment situation, it was found that patients who were currently unemployed had an higher average percentage in the activities domain. In this case, the differences between the groups are statistically significant in the impact domain and total QOL, as revealed Kruskal Wallis test (see Table 4).

These results lead to the partial acceptance of the hypothesis that socio-demographic variables influence the quality of life of patients with COPD.

\subsection{Relationship between quality of life and circum- stantial variables context}

We proceeded to study the relationship between quality of life variable and circumstantial characteristics: accessibility to health services, distance to health services and help from health professionals at home.

With regard to accessibility to health services, it was found that patients, who were transported by firefighters, had the highest average percentage in the activities domain $(84.56 \%)$. In this case, the differences are statistically significant in the impact domain, with the remaining nonsignificant, as demonstrated by the Kruskal - Wallis test.

With regard to the distance to the health service, it was found that the activities domain pondered with a greater mean percentage; patients who were at a distance of more than $8 \mathrm{~km}$, had a higher mean value percentage $(82.15 \%)$. In this case, the differences are statistically significant in the symptoms domain, very significant in the activities and impact domain, and highly significant in the total QOL, as shown ANOVA (see Table 5).

The hypothesis that circumstantial characteristics influencing quality of life of patients with COPD is partially accepted in confrontation of the results mentioned below.

\subsection{Relationship between quality of life and clinical characteristics}

We proceeded to study the relationship between the variable quality of life and clinical characteristics (time of diagnosis, stage of disease, domiciliary oxygen therapy and smoking).

Regarding the time of diagnosis, it was found that the patients who had their disease diagnosed for over 8 years, which had a higher mean percentage in the activities domain $(81.09 \%)$, the symptoms domain $(60.29 \%)$, the impact domain $(58.20 \%)$ as well as in total QOL (65.49\%). So, patients with COPD who have their disease diagnosed longest are those with worse quality of life. We found that the time of diagnosis of the disease has a significant effect on quality of life of patients with COPD, in the activities domain and quite significant in the impact domain and overall QOL, which is confirmed by ANOVA.

Analysis groups related to stage of disease, it was found that patients with stage IV were those with higher average percentage value in the activities domain (82.53\%), the symptom domain $(61.49 \%)$, the impact domain $(60.86 \%)$ and total QOL (67.78\%). Therefore, patients with very severe COPD (stage IV) have a worse quality of life compared with 
patients with stage II and III. In this case, the stage of the main and highly significant in the impact domain and overall disease exerts a very significant effect on the activities do- QOL. This was confirmed by ANOVA.

Table 4: Relationship between quality of life and socio-demographic variables

\begin{tabular}{|c|c|c|c|c|c|c|c|c|}
\hline \multirow{2}{*}{ Variables } & \multicolumn{2}{|c|}{ Symptoms domain } & \multicolumn{2}{|c|}{ Activities domain } & \multicolumn{2}{|c|}{ Impact domain } & \multicolumn{2}{|c|}{ Total QDV } \\
\hline & $\overline{\bar{X}}$ & Dp & $\bar{X}$ & Dp & $\bar{X}$ & Dp & $\overline{\bar{X}}$ & Dp \\
\hline \multicolumn{9}{|l|}{ Age } \\
\hline$\leq 65$ years & 54.06 & 22.44 & 71.85 & 21.02 & 44.43 & 18.69 & 54.34 & 16.97 \\
\hline $66-71$ years & 59.58 & 20.08 & 70.19 & 14.65 & 49.51 & 16.96 & 57.86 & 14.43 \\
\hline $72-78$ years & 59.52 & 15.98 & 73.83 & 21.04 & 49.75 & 17.24 & 58.67 & 16.52 \\
\hline \multirow[t]{3}{*}{$\geq 79$ years } & 60.99 & 20.97 & 84.95 & 16.05 & 64.08 & 17.07 & 69.89 & 14.45 \\
\hline & \multicolumn{2}{|l|}{$F=0.454$} & \multicolumn{2}{|c|}{$F=2.767$} & \multicolumn{2}{|c|}{$F=4.776$} & \multicolumn{2}{|c|}{$F=3.825$} \\
\hline & \multicolumn{2}{|l|}{$p=.715$} & \multicolumn{2}{|c|}{$p=.047$} & \multicolumn{2}{|c|}{$p=.004$} & \multicolumn{2}{|c|}{$p=.013$} \\
\hline \multicolumn{9}{|l|}{ Marital status } \\
\hline Married & 57.68 & 20.23 & 73.06 & 19.34 & 50.22 & 18.88 & 58.52 & 16.71 \\
\hline Single & 56.69 & 8.18 & 94.88 & 6.79 & 65.06 & 14.09 & 72.71 & 8.83 \\
\hline \multirow[t]{3}{*}{ Widow } & 64.91 & 20.39 & 81.60 & 13.33 & 59.10 & 16.60 & 66.89 & 13.43 \\
\hline & \multirow{2}{*}{\multicolumn{2}{|c|}{$\begin{array}{l}F=0.640 \\
p=.530\end{array}$}} & \multirow{2}{*}{\multicolumn{2}{|c|}{$\begin{array}{l}F=3.423 \\
p=.038\end{array}$}} & \multirow{2}{*}{\multicolumn{2}{|c|}{$\begin{array}{l}F=2.118 \\
p=.127\end{array}$}} & \multirow{2}{*}{\multicolumn{2}{|c|}{$\begin{array}{l}F=2.514 \\
p=.088\end{array}$}} \\
\hline & & & & & & & & \\
\hline \multicolumn{9}{|l|}{ Height } \\
\hline$\leq 1.62 \mathrm{~m}$ & 66.00 & 16.74 & 75.69 & 16.15 & 53.78 & 15.12 & 62.45 & 12.83 \\
\hline $1.63-1.66 \mathrm{~m}$ & 58.19 & 20.56 & 76.80 & 16.07 & 53.23 & 18.86 & 61.50 & 15.85 \\
\hline \multirow[t]{3}{*}{$\geq 1.67 \mathrm{~m}$} & 50.82 & 19.86 & 73.30 & 24.34 & 49.28 & 22.24 & 56.84 & 20.17 \\
\hline & \multirow{2}{*}{\multicolumn{2}{|c|}{$\begin{array}{l}F=4.189 \\
p=.019\end{array}$}} & \multirow{2}{*}{\multicolumn{2}{|c|}{$\begin{array}{l}F=0.227 \\
p=.797\end{array}$}} & $F=0.4$ & & $F=0.8$ & \\
\hline & & & & & $p=.64$ & & $p=.423$ & \\
\hline Residence & & & & & & & & \\
\hline Village & 59.95 & 22.47 & 81.99 & 15.78 & 56.79 & 17.52 & 64.96 & 14.94 \\
\hline Town & 49.99 & 21.02 & 67.88 & 28.37 & 48.84 & 24.12 & 54.80 & 22.59 \\
\hline City & 60.12 & 17.32 & 74.08 & 14.59 & 50.91 & 16.58 & 59.69 & 13.63 \\
\hline & $F=1.214$ & & $F=3.28$ & & $F=1.4$ & & $F=2.0$ & \\
\hline & $p=.303$ & & $p=.043$ & & $p=.25$ & & $p=.13$ & \\
\hline Mean cohabitar & & & & & & & & \\
\hline Husband/Wife & 58.29 & 20.39 & 74.23 & 18.34 & 51.18 & 18.47 & 59.49 & 16.14 \\
\hline Father/Mother & 49.81 & 10.51 & 95.22 & 8.28 & 60.89 & 13.75 & 69.45 & 7.82 \\
\hline Child & 67.59 & 21.72 & 85.24 & 10.58 & 65.87 & 10.17 & 72.02 & 8.82 \\
\hline Single & 56.32 & 17.17 & 75.59 & 17.87 & 50.43 & 19.62 & 59.03 & 16.96 \\
\hline & $\chi^{2}=2.112$ & & $\chi^{2}=6.7$ & & $\chi^{2}=5.8$ & & $\chi^{2}=5.8$ & \\
\hline & $p=.348$ & & $p=.035$ & & $p=.05$ & & $p=.05$ & \\
\hline $\begin{array}{l}\text { Employment } \\
\text { situation }\end{array}$ & & & & & & & & \\
\hline Employed & 50.61 & 23.55 & 70.26 & 14.64 & 39.61 & 14.81 & 50.73 & 13.09 \\
\hline Unemployed & 55.25 & 37.65 & 77.97 & 31.16 & 44.13 & 14.15 & 56.23 & 10.69 \\
\hline Retired & 60.09 & 18.87 & 77.09 & 18.22 & 55.31 & 17.89 & 62.84 & 15.77 \\
\hline & $\chi^{2}=1.309$ & & $\chi^{2}=2.0$ & & $\chi^{2}=7.6$ & & $\chi^{2}=6.5$ & \\
\hline & $p=.520$ & & $p=.354$ & & $p=.02$ & & $p=.03$ & \\
\hline
\end{tabular}

Note. U refers to the Mann-Whitney test; $F$ refers to the ANOVA test; $\chi^{2}$ refers to the Kruskal - Wallis test

In respect to domiciliary oxygen therapy, it was found in those patients that had performed this therapy, had a higher mean percentage in the activities domain $(83.74 \%)$, the symptoms domain (63.91\%), the impact domain (62.84\%) and total QOL (69.58\%). The domiciliary oxygen therapy is associated with worse quality of life, verifying that the fulPublished by Sciedu Press fillment of this therapy at home had a significant effect on quality of life of patients with COPD, in the symptoms domain and highly significant in other domains (activities and impact) and QOL total. This was confirmed by the MannWhitney test.

. 
Table 5: Relationship between quality of life and circumstantial variables context

\begin{tabular}{|c|c|c|c|c|c|c|c|c|}
\hline \multirow{2}{*}{ Variables } & \multicolumn{2}{|c|}{ Symptoms domain } & \multicolumn{2}{|c|}{ Activities domain } & \multicolumn{2}{|c|}{ Impact domain } & \multicolumn{2}{|c|}{ Total QDV } \\
\hline & $\bar{X}$ & Dp & $\bar{X}$ & Dp & $\bar{X}$ & Dp & $\bar{X}$ & Dp \\
\hline $\begin{array}{l}\text { Accessibility to health } \\
\text { services }\end{array}$ & 57.22 & 22.09 & 73.55 & 17.44 & 46.73 & 15.59 & 56.62 & 14.19 \\
\hline Transport itself & 59.16 & 20.14 & 75.29 & 19.69 & 55.86 & 19.88 & 62.53 & 17.75 \\
\hline Public transport & 65.86 & 10.84 & 82.06 & 7.71 & 62.99 & 14.41 & 69.24 & 10.55 \\
\hline \multirow[t]{3}{*}{ Firefighters } & 57.08 & 17.14 & 84.56 & 15.11 & 54.85 & 17.04 & 64.23 & 12.74 \\
\hline & \multicolumn{2}{|c|}{$\chi^{2}=1.026$} & \multicolumn{2}{|c|}{$\chi^{2}=4.581$} & \multicolumn{2}{|c|}{$\chi^{2}=8.156$} & \multicolumn{2}{|c|}{$\chi^{2}=6.187$} \\
\hline & \multicolumn{2}{|c|}{$p=.795$} & \multicolumn{2}{|c|}{$p=.205$} & \multicolumn{2}{|c|}{$p=.043$} & \multicolumn{2}{|c|}{$p=.103$} \\
\hline \multicolumn{9}{|l|}{$\begin{array}{l}\text { Distance to the health } \\
\text { service }\end{array}$} \\
\hline$\leq 3 \mathrm{~km}$ & 50.91 & 22.49 & 66.48 & 22.71 & 41.99 & 19.48 & 50.89 & 18.31 \\
\hline $4-7 \mathrm{~km}$ & 60.96 & 15.62 & 77.36 & 13.48 & 55.03 & 16.43 & 63.06 & 12.96 \\
\hline \multirow[t]{3}{*}{$\geq 8 \mathrm{~km}$} & 63.93 & 19.57 & 82.15 & 16.88 & 59.49 & 16.19 & 67.12 & 13.61 \\
\hline & \multicolumn{2}{|c|}{$F=3.235$} & \multicolumn{2}{|c|}{$F=5.147$} & \multicolumn{2}{|c|}{$F=7.040$} & \multicolumn{2}{|c|}{$F=8.086$} \\
\hline & \multicolumn{2}{|c|}{$p=.045$} & \multicolumn{2}{|c|}{$p=.008$} & \multicolumn{2}{|c|}{$p=.002$} & \multicolumn{2}{|c|}{$p=.001$} \\
\hline
\end{tabular}

Note. $F$ refers to the ANOVA test; $\chi^{2}$ refers to the Kruskal - Wallis test

Table 6: Relationship between quality of life and clinical variables

\begin{tabular}{|c|c|c|c|c|c|c|c|c|}
\hline \multirow{2}{*}{ Variables } & \multicolumn{2}{|c|}{ Symptoms domain } & \multicolumn{2}{|c|}{ Activities domain } & \multicolumn{2}{|c|}{ Impact domain } & \multicolumn{2}{|c|}{ Total QDV } \\
\hline & $\bar{X}$ & Dp & $\bar{X}$ & Dp & $\bar{X}$ & Dp & $\bar{X}$ & Dp \\
\hline \multicolumn{9}{|c|}{ Time of diagnosis } \\
\hline$\leq 3$ year olds & 56.75 & 20.51 & 66.32 & 16.68 & 41.97 & 17.59 & 51.80 & 15.51 \\
\hline 4-7 year olds & 58.49 & 17.44 & 77.13 & 15.13 & 54.81 & 15.15 & 62.51 & 12.34 \\
\hline \multirow[t]{3}{*}{$\geq 8$ year olds } & 60.29 & 21.81 & 81.09 & 21.38 & 58.20 & 19.62 & 65.49 & 17.99 \\
\hline & \multicolumn{2}{|c|}{$F=0.206$} & \multicolumn{2}{|c|}{$F=4.585$} & \multicolumn{2}{|c|}{$F=6.035$} & \multicolumn{2}{|c|}{$F=5.480$} \\
\hline & \multicolumn{2}{|c|}{$p=.814$} & \multicolumn{2}{|c|}{$p=.013$} & \multicolumn{2}{|c|}{$p=.004$} & \multicolumn{2}{|c|}{$p=.006$} \\
\hline \multicolumn{9}{|c|}{ Stage of disease } \\
\hline II & 54.58 & 24.11 & 69.38 & 23.09 & 45.18 & 20.55 & 54.07 & 19.25 \\
\hline III & 58.71 & 15.89 & 69.50 & 11.96 & 44.95 & 12.66 & 54.68 & 9.61 \\
\hline \multirow[t]{3}{*}{ IV } & 61.49 & 18.14 & 82.53 & 16.02 & 60.86 & 16.38 & 67.78 & 13.93 \\
\hline & \multicolumn{2}{|c|}{$F=0.917$} & \multicolumn{2}{|c|}{$F=5.288$} & \multicolumn{2}{|c|}{$F=8.370$} & \multicolumn{2}{|c|}{$F=7.842$} \\
\hline & \multicolumn{2}{|c|}{$p=.404$} & \multicolumn{2}{|c|}{$p=.007$} & \multicolumn{2}{|c|}{$p=.001$} & \multicolumn{2}{|c|}{$p=.001$} \\
\hline \multicolumn{9}{|c|}{ Home oxygen therapy } \\
\hline Yes & 63.91 & 15.73 & 83.74 & 15.69 & 62.84 & 15.49 & 69.58 & 12.86 \\
\hline \multirow[t]{3}{*}{ No } & 54.29 & 21.88 & 68.44 & 18.61 & 43.47 & 16.54 & 52.84 & 15.16 \\
\hline & \multicolumn{2}{|c|}{$\mathrm{U}=576.000$} & \multicolumn{2}{|c|}{$\mathrm{U}=422.000$} & \multicolumn{2}{|c|}{$\mathrm{U}=302.000$} & \multicolumn{2}{|c|}{$\mathrm{U}=304.000$} \\
\hline & $p=.037$ & & $p=.000$ & & $p=.000$ & & $p=.000$ & \\
\hline \multicolumn{9}{|c|}{$\begin{array}{l}\text { Current smoking } \\
\text { habits }\end{array}$} \\
\hline Yes & 55.68 & 19.05 & 67.74 & 21.76 & 46.92 & 22.12 & 55.01 & 19.68 \\
\hline \multirow[t]{2}{*}{ No } & 59.96 & 20.21 & 78.77 & 16.49 & 54.58 & 16.58 & 62.82 & 14.19 \\
\hline & $\begin{array}{l}\mathrm{U}=606 \\
p=.398\end{array}$ & & $\begin{array}{l}\mathrm{U}=488 \\
p=.038\end{array}$ & & $\begin{array}{l}\mathrm{U}=560 \\
p=.186\end{array}$ & & $\begin{array}{l}\mathrm{U}=532 \\
p=.107\end{array}$ & \\
\hline
\end{tabular}

Note. $\mathrm{U}$ refers to the Mann-Whitney test; $F$ refers to the ANOVA test

With regard to current smoking habits, it was found that the activities domain pondered with the highest average percentage, being patients who did not possess these habits to- day, those with higher value (78.77\%), with a statistically significant difference in this domain, which was demonstrated by the Mann-Whitney test (see Table 6). 
These results lead to the partial acceptance of the hypothesis that the clinical characteristics influencing quality of life of patients with COPD.

\subsection{Relationship between quality of life and family functioning}

We proceeded to study the relationship between the variable quality of life and family functioning, and the results obtained led to the rejection of the hypothesis, that family functioning influences the quality of life of patients with COPD.

\section{Discussion}

Knowing widely that the processes of health and disease contain multiple lines of research that can be explored, the literature review conducted showed that the subject of respiratory rehabilitation and respective effects in patients with COPD being at a stage something developed in terms of research. The general trend has been over the past few decades to consider this therapy as a strictly enrolled reality to the context of worsening in hospital while neglecting the use in the context inter exacerbations.

Indeed, the socio-demographic changes that have occurred in Western societies have resulted in an aging population and increasing adoption of habits and unhealthy life, which has led to proliferation of pathologies associated with them, experiencing some difficulties in treatment and control. This reality has created a important pressure in terms of health systems, requiring special attention on the part of care services, on gains in health (respiratory) and quality of life.

\subsection{Sample characterization of patients with COPD}

The analysis of results for the socio-demographic characteristics of the sample allows to check which are the predominate males $(81.2 \%)$. These results are in line with data reported by the DGS, ${ }^{[12]}$ which states that this respiratory disease primarily affects men. In regards to age, the mean 70.89 years $(S D=10.52)$ meets the data presented by DGS, ${ }^{[12]}$ which states that the prevalence of COPD increases with age, reaching $13 \%$ of the population aged over 60 years. The profile of patients with COPD are married $(81.2 \%)$, live with the respective spouse $(78.8 \%)$, and reside in urban areas $(50 \%)$. Concering the nutritional characteristics, it was found that patients with COPD had an average weight $68.58 \mathrm{~kg}$, and an average height of $1.64 \mathrm{~m}$. This also dominates a low level of education $(43.87 \%$ possess only the 4 th grade), low current monthly earnings ( $85 \%$ earns a lower monthly earnings to 419.22 euros) being most retired individuals $(83,3 \%)$. Only $14.1 \%$ of subjects develop a professional activity today, with the majority of these activities falling within the primary sector $(86.2 \%)$.

Regarding circumstantial characterization, the distance separating the sick from the nearest health service is on average
$7.39 \mathrm{~km}(S D=7.05)$, and most of them (43.8\%) use transport family to make this move. It was also found that the vast majority of patients $(93.8 \%)$ did not have any help at home. Concerning the clinical characterization, it was found that the mean time to diagnosis was 7.53 years $(S D=7.47)$. Regarding the severity of the disease, it was found that most respondents $(45 \%)$ had a very severe COPD (stage IV), and the same percentage of individuals also execute domiciliary oxygen therapy (45\%). On average, these patients perform Oxygen 16.24 hours per day. These results are in line with what is stated by the DGS, ${ }^{[12]}$ when refering to the fact that COPD is responsible for the long use of domiciliary oxygen therapy. With regard to smoking, if was found that $68.8 \%$ of patients do not have smoking habits nowadays, however the vast majority $(80 \%)$ will have had these habits in the past, with a calculating the mean time of smoke exposure about 23.10 years.

These results are consistent with what the DGS, ${ }^{[12]}$ states when referring to the increasing prevalence of COPD associated with increased prevalence of smoking, becoming this risk factor as the main cause. Also Torres and Godoy ${ }^{[19]}$ and GOLD,${ }^{[20]}$ reiterates that smoking is the most important causative environmental factor for COPD, with greater influence on quality of life.

It was found that on average, patients had 0.98 admissions in the last year related to their breathing problem and patients who did not comply pulmonary rehabilitation those who have a higher mean number of hospitalizations (1.31) in the last year. These data are in line with what is referred to by DGS, ${ }^{[12]}$ when he states that COPD is responsible for a significant number of resource to emergency services, as well as, often prolonged hospitalizations.

Predominate individuals currently taking medication directed to the respiratory, cardiovascular and metabolic disorders, take this medication on a regular basis. In this respect also the DGS, ${ }^{[12]}$ states that, in fact, COPD is associated with the use of medicines of long duration.

\subsection{The quality of life in patients with COPD}

In the present study was analysed the quality of life of a group of patients with COPD undergoing respiratory rehabilitation was analysed, through a specific questionnaire (SGRQ), achieving levels of quality of life concerning areas that make up this analyzed instrument.

The results showed that all participants in this study have a compromised quality of life in all domains (symptoms, activity, impact).

In total quality of life, was ascertained that the mean percentage values of quality of life was $60.38 \%$, showing therefore a condition of abnormality, in the light of the author's interpretation of the scale when refers that values obtained until $10 \%$ show that the quality of life is still considered nor- 
mal, whereas results above $10 \%$ indicate an abnormal condition. ${ }^{[15]}$ The data obtained in this study are in line with what concerns the ONDR, ${ }^{[4]}$ Vasconcelos et al., ${ }^{[5]}$ and António et al. ${ }^{[21]}$ when they state that COPD causes a number of changes, with unambiguous translation in the progressive deterioration of the quality of life of the patient. Similar results were also found by Pagani. ${ }^{[3]}$

By analyzing the allocation of domains, and knowing the author's interpretation of the scale, considering that values near to 100 indicate worse quality of life, to highlight the existence of a significant impairment in all areas, being more pronounced in the activities domain $(75.32 \%)$, followed by the symptom domain $(58.62 \%)$, and finally the impact domain $(52.19 \%)$.

In parallel, analyzing the results in light of the implementation of a rehabilitation program, it was found a greater impairment of quality of life was found in patients who were not submitted to this therapy, presenting, therefore, mean values higher percentages in all areas: symptoms $(58.87 \%$ to $58.35 \%)$; activity $(78.31 \%$ to $72.02 \%)$, impact $(53.58 \%$ to $50.65 \%)$ and total QOL (62.16\% to $58.41 \%)$. These data translate, clearly, benefits from the realization of respiratory rehabilitation, as told by Maltais et al., ${ }^{[22]}$ Linda et al., ${ }^{[1]}$ Clement et al., ${ }^{[23]}$ Vettorazzi, ${ }^{[8]}$ Pamplona et al., ${ }^{[24]}$ and António et al. ${ }^{[21]}$

The level of involvement in the activities domain identified in this study are in the considerations made by the DGS, ${ }^{[12]}$ when said there was a tendency for the significant increase in loss of functionality due to acute exacerbations and hospitalizations in patients with COPD. Moreover, also the $\mathrm{WHO},{ }^{[25]}$ states peremptorily that the decreased mobility, is a situation that is often seen in patients with respiratory disorders, worsening the welfare and self-sufficiency, with losses for the capacity of performance the activities of daily living.

The SGRQ showed a greater involvement of women in all domains and total QOL compared with men, not however without significant differences. This greater impairment in women relative to men was also identified in investigations related breathing disorders carried out in recent years, presumably associated with the fact that women live on average more years than men, thence a decrease from autonomyrelated age. ${ }^{[26]}$

In parallel, the elderly had higher allocation in theactivities domain $(84.95 \%)$, the impact domain $(64.08 \%)$ and total QOL $(69.89 \%)$ when compared with the less elderly. In this case, age has a significant effect on activities domain and total QOL, and very significant in the impact domain. The data as a whole are consistent with those obtained in other studies.

It was found that patients who live in rural areas have a worse quality of life $(81.99 \%)$ with respect to the activities domain and it was found that the residence exerts a significant effect on the quality of life of patients with COPD in this field.

Those patients who live at a greater distance from the health service have worse quality of life, verifying that this distance has a significant effect on the quality of life of patients with COPD, in the symptoms domain; quite significant in activities and impact domains, and highly significant in the total QOL. These results lead us to the idea that the proximity of health and care services, in case of need it is desirable, providing feelings of greater safety, and welfare, going to what is exposed by Lemos et al. cit. in Pagani, [3] When stating that the quality of life is a multidimensional concept, involving physical, social and emotional aspects.

It was found that patients who live with their father / mother have a higher affectation in the activities domain $(95.22 \%)$. In parallel, we also found that patients who are living with children have greater impairment in other domains and total QOL. In this case, the mean cohabitant has a significant effect on the quality of life of patients with COPD, in the activity domain, impact and total QOL. Although in the literature, they are not data that could be compared to those obtained in this study, it is attributed to these results, factors as older age, presence of co-morbidities and chronic nature of this disease, which imposes the need for continued treatment a long period, involving monitoring and surveillance by family.

It was found that patients with COPD who have their disease diagnosed the longest are those with worse quality of life. In this case, it was found that the time of diagnosis of the disease has a significant effect on the quality of life of patients with COPD, in the activities domain and quite significant in the impact domain and total QOL. These results are in line with what is narrated by António et al., ${ }^{[21]}$ and ONDR, ${ }^{[4]}$ with regard to the disease progresses with gradual worsening of symptoms and limitation of exercise tolerance, with a progressive deterioration of translation quality of life of the patient.

It was observed that patients with very severe COPD (stage IV) have a worse quality of life, than patients with stage II and III. In this case, the stage of disease is very significant in the activities domain and highly significant in the impact domain and total QOL. These results are congruent with what is exposed by Rodrigues and Ferreira, ${ }^{[17]}$ DGS, ${ }^{[12]}$ GOLD,${ }^{[27]}$ and Couto, ${ }^{[7]}$ when referring to the fact that COPD evolve progressively and irreversibly, with exacerbations, whose frequency increases with the severity of the disease, leading to disability, with a marked negative impact on quality of life of patients.

It was found that the performance of domiciliary oxygen therapy is associated with worse quality of life, thus verifying that the implementation of this therapy at home has a significant effect on the quality of life of patients with 
COPD, in the symptoms domain and highly significant in other areas (activities and impact) and overall QOL. This information is particularly important when we reflect on the fact that the administration of oxygen for several consecutive hours, involve the requirement of the patient being confined, often to only one room in the house, with reduced dimensions, therefore limiting the performance of other activities of daily living. Similar results were also found by Anderson, ${ }^{[28]}$ when referring to the gravity of the disease which has a significant effect on quality of life.

In summary, the research carried out showed that the sample of patients with COPD have a compromised quality of life, being the activities the most affected area, thus providing clear guidelines for the planning and performance of integrated interventions. Also it was found that patients who did not comply with the respiratory rehabilitation program have worse quality of life than those who have completed this therapy.

\subsection{Conclusion}

In many countries, the proliferation of chronic respiratory diseases have faced difficulties in their treatment and control. In this context, COPD emerges as a condition that greatly affects the activities of daily living, with clear impact on the quality of life of each one. Due to this reality, respiratory rehabilitation has an important role in the objectification of improved survival and quality of life of patients affected with changes in respiratory disorders, emerging as a topic of great relevance.

The recourse to respiratory rehabilitation as coadjuvant of pharmacological therapy is being a treatment strategy of patients with chronic respiratory disease that was certainly well documented over the past two decades, in regard to COPD. The large number of cases, meta-analyzes or systematic reviews, as well as conferences and guidelines published to date, show of one consistent manner, the benefits of this therapy.

The present study aimed to assess the quality of life of patients with COPD undergoing respiratory rehabilitation. The research carried out showed that the sample of patients with COPD have a compromised quality of life in all domains (symptoms, activity, impact), with a greater impairment in patients who were not submitted to respiratory rehabilitation.

From here derives the need for an integrated planning of interventions with multidisciplinary teams, with a view to bigger and better suitability of care, particularly nursing rehabilitation care.

It is believed that health research, specifically in the area of quality of life is a fundamental foundation for the promotion of best practices in health.

Thus, we pretend to promote the involvement of various professionals in the application of the results of this and other previous studies. What is intended, are increasingly integrated interventions, multidisciplinary and patient-centered.

\section{Conflicts of Interest Disclosure}

The author declares that there is no conflict of interest statement.

\section{References}

[1] Linda N. et al. American Thoracic Society, European Respiratory Society Statement on Pulmonary Rehabilitation; American Journal of Respiratory and critical care Medicine. 2006; 173: 13901413. PMID:16760357 http://dx.doi.org/10.1164/rccm. 20 0508-1211ST

[2] Araújo, A. T. (s.d.). Epidemiologia da DPOC em Portugal e no mundo.

[3] Pagani, N.- Percepção sobre qualidade de vida em pacientes portadores de Doença Pulmonar Obstrutiva Crónica. UnB - Faculdade de Ciências da Saúde. Dissertação de Mestrado em Ciências da Saúde. $2008 ; 86$.

[4] Observatório Nacional das Doenças Respiratórias - Relatório Preliminar do Observatório Nacional das Doenças Respiratórias. Relator: A. Teles de Araújo. 2005.

[5] Vasconcelos, $\mathrm{R}$ et al. - A actuação da fisioterapia na doença pulmonar obstrutiva crónica. Fisioweb. Brasil 2005;

[6] Ramos-Cerqueira, Ana Teresa; Crepaldi, André Luiz- Qualidade de vida em doentes pulmonares crónicas: aspectos conceituais e metodológicos. J.Pneumol. 2000; 26 (4): 207-213. http://dx.d oi.org/10.1590/S0102-35862000000400008
[7] Couto, Tatiana - Caracterização da qualidade de vida e necessidades de idosos com DPOC. Universidade de Aveiro Secção Autónoma de Ciências da Saúde, Dissertação de Mestrado; 2010.

[8] Vettorazzi, Suzana; Teixeira, Paulo - Implantação e resultados de um programa de reabilitação pulmonar numa instituição de ensino superior. Universidade Federal do Rio Grande do Sul. Faculdade de Medicina. Programa de Pós-Graduação em Medicina : Pneumologia. 2006.

[9] Pedhazur, E. J.; Schmelkin, L. - Measurement, design and analysis: an integrated approach. New York: Lawrence Earlbaum Associates. 1991.

[10] Kiess, H. O.; Bloomquist, D. N. - Psychological research methods: a conceptual approach. Londres: Allyn and Bacon. 1985.

[11] Gil, António Carlos - Métodos e Técnicas de Pesquisa Social. $4^{\mathrm{a}}$. ed. São Paulo: Atlas; 1995.

[12] Direção Geral da Saúde - Programa Nacional de Prevenção e Controlo da Doença Pulmonar Obstrutiva Crónica. Circular Normativa $\mathrm{n}^{\circ}$ 04/DGCG. Ministério da Saúde, 2005.

[13] Hillers, TK. et al. - Quality of life after myocardial infarction. Journal Clinical Epidemiology. 1994; 47(11): 1287-1296. http: //dx.doi.org/10.1016/0895-4356(94)90134-1

[14] Oldridge, $\mathrm{N}$ et al. - Predists of health related quality of life with cardic rehabilitation after acute myocardial infarction. Journal of cardiopulmonary rehabilitation. 1998; 18: 95-103. PMID:9559446 http://dx.doi.org/10.1097/00008483-199803000-00002 
[15] Jones, PW., Quirk, FH. e Baveystock, CM. - The St George's Respiratory Questionnaire. Respir Med. 1991; 85 Suppl B: 25-31.

[16] Sousa, TC de., Jardim, JR. e Jones, P. - Validação do questionário do Hospital Saint George na Doença Respiratória (SGRQ) em pacientes portadores de doença pulmonar obstrutiva crónica no Brasil. Jornal Brasileiro de Pneumologia, Ribeirão Preto. 2000; 26(3): 119-128. http://dx.doi.org/10.1590/S0102-35862000000300004

[17] Rodrigues, F. e Fereira, R. - Epidemiologia da DPOC em Portugal. Postgraduate Medicine, Edição Portuguesa. 2003; 20(4).

[18] Azeredo, Z.; Matos, E.- Avaliação do relacionamento do idoso em medicina familiar. Geriatria. Lisboa. 1998; 2(20): 28.

[19] Torres, B.S. e Godoy, I. - Diretrizes para cessação do tabagismo. Jornal Brasileiro de Pneumologia, Ribeirão Preto. 2004; 30(2).

[20] Gold (Global Initiative for Chronic Obstructive Lung Disease) Global strategy for the Diagnosis, Management, and Prevention of Chronic Obstructive Pulmonar Disease. 2007.

[21] António, C. et al - Doença pulmonar obstrutiva crónica e exercício físico. Rev Port Pneumol. 2010. PMID:20700562

[22] Maltais F, Hershfield S, Stubbing D et al. Exercise Training in Patients with COPD. In Comprehensive management of Chronic Obstructive Pulmonary Disease; BC Decker inc. 2002; 185-214.
[23] Clemente S, Faria I, Rodrigues F; O treino de Exercício e o Doente com DPOC, Boletim do HPV. 2006.

[24] Pamplona P, Morais L; Treino de exercício na Doença Pulmonar crónica; Revista Portuguesa de Pneumologia. 1998.

[25] Organização Mundial de saúde Relatório Mundial de Saúde 2001 - Saúde mental: nova concepção, nova esperança. M.d. Saúde, Ed. Lisboa: Direcção-Geral da Saúde. 2002.

[26] Sousa, L.; Galante, H. e Figueiredo, D. - Qualidade de vida e bemestar dos idosos - um estudo exploratório na população portuguesa. Revista de Saúde Pública. 2003; 37: 364-371. http://dx.doi.o rg/10.1590/S0034-89102003000300016

[27] Gold (Global Initiative for Chronic Obstructive Lung Disease)Global Strategy for the Diagnosis, Management, and Prevention of Chronic Obstructive Pulmonary Disease. 2006.

[28] Anderson, $\mathrm{kl}$ - The effect of chronic obstructive pulmonar disease on quality of life. Res Nurs Health. 1995; 18: 547556. PMID:7480855 http://dx.doi.org/10.1002/nur.47701 80610 